\title{
MAXIMUM PERIODIC WAVE RUNUP ON SMOOTH SLOPES
}

by

Todd L. Walton, Jr., John P. Ahrens

Coastal Engineering Research Center

DEPARTMENT OF THE ARMY

Waterways Experiment Station, Corps of Engineers

3909 Halls Ferry Road, Vicksburg, Mississippi 39180-6199

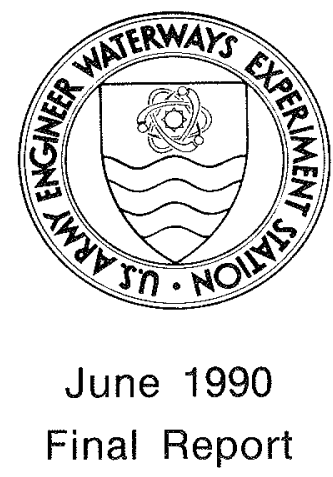

Approved For Public Release; Distribution Unlimited

Prepared for DEPARTMENT OF THE ARMY

US Army Corps of Engineers

Washington, DC 20314-1000 
When this report is no longer needed return it to the originator.

The findings in this report are not to be construed as an official Department of the Army position unless so designated by other authorized documents.

The contents of this report are not to be used for advertising, publication, or promotional purposes. Citation of trade names does not constitute an official endorsement or approval of the use of such commercial products. 
Unclassified SECURITY CLASSIFICATION OF THIS PAGE

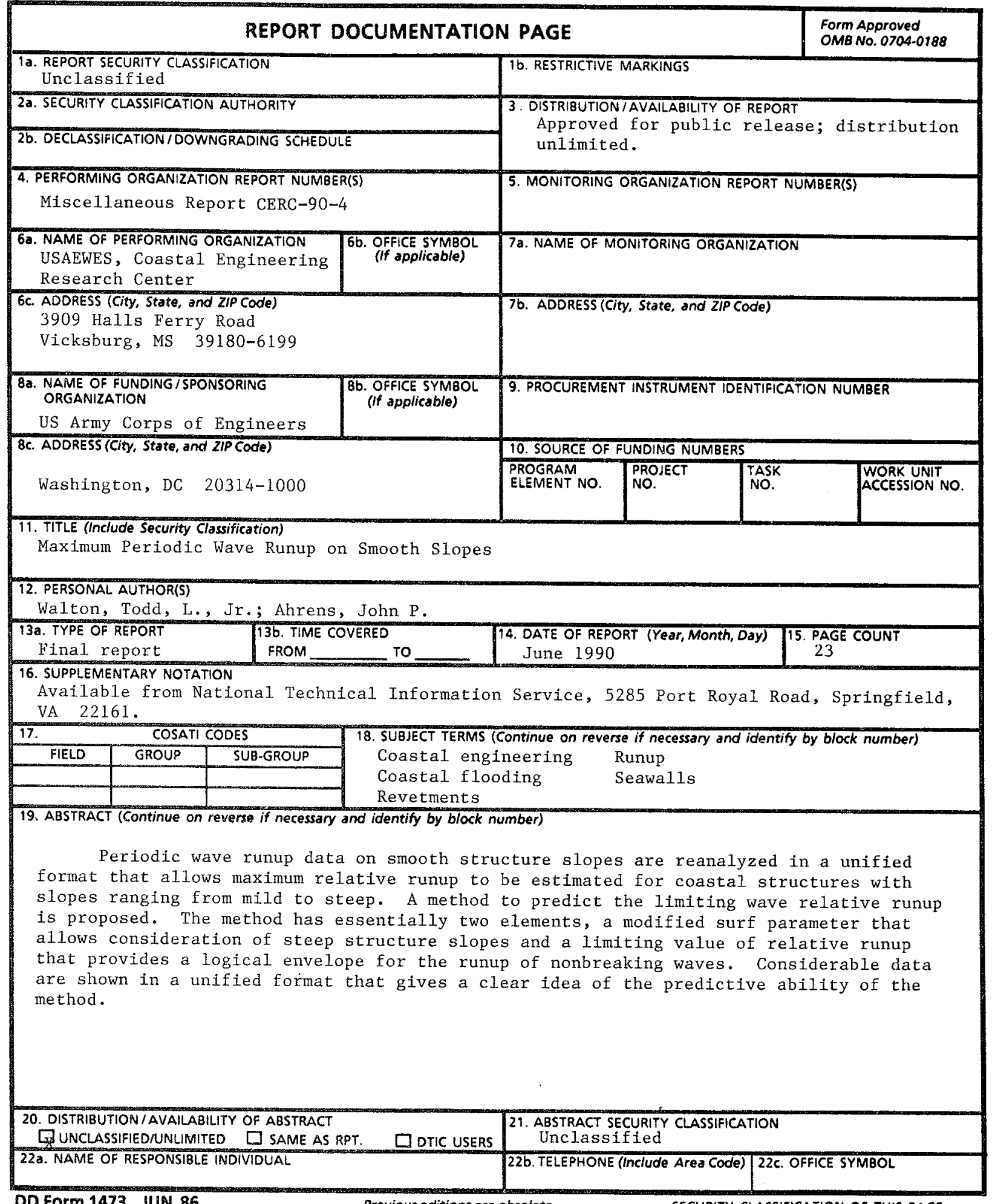




\section{Preface}

The investigation described in this report was authorized as part of the Civil Works Research and Development Program by Headquarters, US Army Corps of Engineers (HQUSACE). This study was conducted by the Work Unit 32531, "Irregular Wave Runup on Beaches," under the Shore Protection and Restoration Program at the Coastal Engineering Research Center (CERC) of the US Army Engineer Waterways Experiment Station (WES). Messrs. John H. Lockhart, Jr., John G. Housley, and James E. Crews were the HQUSACE Technical Monitors.

Dr. C. Linwood Vincent is CERC Program Manager.

The study was conducted from October 1988 through May 1989 by

Dr. Todd L. Walton, Jr., Hydraulic Engineer, CERC, and Mr. John Ahrens, Oceanographer, CERC.

This study was done under general supervision of Dr. James R. Houston, and Mr. Charles C. Calhoun, Jr., Chief and Assistant Chief, CERC, respectively; and under direct supervision of Mr. Thomas W. Richardson, Chief, Engineering Development Division, CERC.

Commander and Director of WES during publication of this report was COL Larry B. Fulton, EN. Dr. Robert W. Whalin was Technical Director. 


\section{Contents}

Preface . . . . . . . . . . . . . . . . . . . . . . .

Introduction. . . . . . . . . . . . . . . . . . . . . . . . . . . 3

Data Sources. . . . . . . . . . . . . . . . . . . . . 4

Analysis Procedure. . . . . . . . . . . . . . . . . . . . 5

Results. . . . . . . . . . . . . . . . . . . . . . . . . 9

Conclusions . . . . . . . . . . . . . . . . . . . . . . . 10

References. . . . . . . . . . . . . . . . . . . . 11

Tables 1-2

Figures 1-9

Appendix A: Notation . . . . . . . . . . . . . . . . . . . . . 
MAXIMUM PERIODIC WAVE RUNUP ON SMOOTH SLOPES

\section{Introduction}

Wave runup is defined as the height above stillwater level to which a wave will rise on a structure or beach. Proper design of coastal structures depends on the ability to make reliable estimates of the maximum runup that might occur on the structure during a significant storm or extreme event. A method is presented in this paper which provides a conservative approach for structures fronted by flat slopes.

Considerable effort has addressed the calculation of wave runup on structures due to short (wind and swell) wave action. Summaries of studies on wave runup for periodic waves using various methods of data presentation were reported in Saville (1956), Savage (1958), Koh and LeMehaute (1966), Van Dorn (1966), Raichlen and Hammock (1974), Battjes (1974), Technical Advisory Committee on Protection Against Inundation (1974), and Stoa (1978). Numerous other references have also been written on the subject dealing with irregular wave runup and/or long wave runup. The present paper presents another approach to data presentation for the case of short monochromatic waves on smooth surface sloping structures with an intent to unify various existing theories and approaches for wave runup and to provide a reasonable means to calculate an upper limit of runup for conservative design practice. A particular shortcoming in much of the early work on runup in the US as summarized in the present runup design curves presented in the US Army Corps of Engineers Shore Protection Manual (1984) is that authors' interpretations of data curves have been shown and the data itself deleted from such curves. The lack of data points does not allow the engineer to estimate accuracy from what scatter might exist. The reanalysis of periodic wave runup data provided in this paper provides the raw data points in a new format. An additional variant in the present reanalysis of runup data is to provide wave runup in terms of wave height at the structure toe depth as opposed to utilizing the deep water wave height. The advantage of utilizing transformed wave height rather than deep water wave height is that wave height transformation uncertainty from deep water to the structure site becomes a separate problem, uncoupled from the problem of what runup actually occurs on the structure due to a given wave at 
the toe of the structure. Although it is recognized that the type (shape) of wave existing at the site is important to the ultimate problem (i.e. the transformation prior to the structure and the ultimate runup are not entirely uncoupled), the presentation of data in terms of wave conditions at the base of the slope should be of benefit to the ultimate user of runup curves who might want to design using depth limited breaking wave height criteria. Since wave period is considered invariant throughout the transformation process, deepwater wave length is still used in the analysis.

\section{Data Sources}

The data sources for this runup reanalysis are from earlier tests at the Coastal Engineering Research Center on smooth slope runup. These data are discussed in length by Saville (1956) and Savage (1958). This same set of data was used by Stoa (1978) in an earlier reanalysis of runup. For purposes of clarification, a short discussion of this data set follows. Further information on these tests can be found in Saville (1956) and Savage (1958).

The test procedure involved placing a smooth surface plywood test slope in the end of the wave tank and propagating periodic waves of known characteristics toward the slope. The waves in each test were measured after the initial unsteady wave transients died down but prior to rereflection of waves from the wave generator. An average of six to fifteen waves were visually measured by reading the runup on a scale marked on the face of the slope to the nearest hundredth of a foot in vertical elevation. In all the data presented in this paper, the water depth was constant $(=0.38$ meters). Saville (1956) noted that varying the water depth at the toe of the structure had a negligible effect on the relative wave runup when the water depth at the toe of the structures was equal to or greater than three times the deep water wave height.

Wave characteristics were determined by calibrating the wave generator for the 0.38 meter water depth. The generator was calibrated by placing a wave absorber in the beach end of the tank and generating a wave train with known and reproducible settings on the generator. The average height of the wave train so generated was measured with a parallel wire gage at 2 meter intervals along the tank beginning near the wave generator. Wave heights were plotted versus distance along the tank and the wave height value obtained from 
a smooth curve drawn thru the points at a distance coinciding with the toe of the test slope was interpolated as the wave height value for that particular generator setting and structure slope. Using the wave height at the structure toe, water depth, and wave period, deepwater wave height was computed from linear wave theory via an inverse transformation. Original runup results were plotted using the deepwater wave height rather than the measured wave height. Wave periods for the test data ranged from 0.72 to 5.00 seconds while wave height ranged from 0.01 to 0.19 meters.

A listing of the data test conditions is provided in Table 1.

\section{Analysis Procedure}

As in all approaches to evaluating laboratory data, there are two methods of determining the important dimensionless groupings of variables for data presentation. A fundamental method for obtaining important dimensionless groupings of parameters often utilized where the physics of the processes are unknown or not well understood is the Buckingham Pi method (see for example White (1979)). This method or a variation of it has been utilized in various studies of runup (see for example Technical Advisory Committee on Protection Against Inundation (1974)). The resulting dimensionless groupings of runup variables for the case of normal wave incidence and linear smooth slope structures of unknown functional form is as follows:

$$
R / H=f\left(H / L_{0}, H / d, \rho H^{3} / \sigma T^{2}, \rho H^{2} / \mu T, A\right)
$$

where $R=$ runup, $H=$ wave height at toe of structure, $L_{0}=$ deepwater wave length, $d=$ water depth at toe of structure, $\rho=$ density of fluid, $\sigma=$ surface tension, $\mu=$ dynamic viscosity, and $A=$ structure slope. The third dimensionless grouping on the RHS (right hand side) of equation 1 is the Weber Number for oscillatory flow which is of negligible importance for models of reasonable size. The fourth dimensionless grouping on the RHS of Equation 1 is the Reynolds Number for oscillatory flow. Projected effects of Reynolds Number are unknown in the present data set. Actual scale effect in runup studies has been investigated by various authors (Saville (1958), Fuhrboter (1986)), but results to date have been insufficient to define such effects well. 
of the remaining three parameters in Equation 1, Iribarren (1949) first noted the importance of the combination of wave steepness $\left(H / L_{0}\right)$ and structure slope (A) in one parameter, the Iribarren number $\left(\tan (A) /\left(H / L_{0}\right)^{1 / 2}\right)$. Various researchers (Galvin (1972), Battjes (1974), Hunt (1959)) have noted the importance of this parameter in both the breaking process and resulting runup on beaches. For mild slope structures Hunt (1959) recognized that the relative runup was proportional to the Iribarren number under breaking wave conditions. Battjes (1974) provides a physical explanation for the relationship between runup and the Iribarren number for the case of mild slope structures. A limitation to this equation can be seen for the case of steep sloped structures where the Irribarren number approaches infinity. In the present paper it is desired to provide a unified approach for wave runup on both steep and mild slope structures, therefore a $\sin (A)$ term was used in place of the $\tan (A)$ of the Iribarren number and hence this modified dimensionless grouping will be referred to as the modified Iribarren number. It should be noted that a slight refinement of Battjes (1974) arguments (i.e. considering wavelength defined along the slope rather than in the horizontal plane) will lead to the $\sin (A)$ term used here. This modification of the Iribarren number is consistent with various criteria for delineation of the zone between breaking and nonbreaking. For example, Munk and Wimbush (1969), provide an expression based on linear wave theory for breaking on a slope in which the downslope component of the particle acceleration cannot exceed $g \sin (A)$. As Battjes (1974) noted, with proper accounting of the reflected wave height, the Munk and Wimbush (1969) criteria can be written as:

$$
\left[\sin (A) /\left(H / L_{0}\right)^{1 / 2}\right]_{c}=(2 \pi)^{1 / 2}
$$

Miche (1951) using linear wave theory also derived a kinematic criterion for the limiting conditions of non-breaking on a plane slope extending to deep water. His criterion is given by:

$$
\left(H_{0} / L_{0}\right)_{c}=\left(\sin ^{2}(A) / \pi\right)(2 A / \pi)^{1 / 2} \text { for } A \leq \pi / 4
$$

This expression can be reformulated as: 


$$
\left[\sin (A) /\left(H / L_{0}\right)^{1 / 2}\right]_{C}=\left(\pi / K_{s}\right)^{1 / 2}(\pi / 2 A)^{1 / 4}
$$

where $K_{s}$ is the linear shoaling coefficient if one assumes the expression good for all depths. Keller (1961) finds a similar expression for limiting conditions for non-breaking where:

$$
\left(H / L_{0}\right)_{c}=K_{s}\left(A^{2} / 2 \pi\right)(2 A / \pi)^{1 / 2}
$$

which can be rewritten as:

$$
\left[A /\left(H / L_{0}\right)^{1 / 2}\right]_{c}=\left(2 \pi / K_{s}\right)^{1 / 2}(\pi / 2 A)^{1 / 4}
$$

Keller's expression is based on a nonlinear shallow water theory and therefore might be considered more valid than the expression of Miche. For small slopes $A=\sin (A)$ and hence Keller's criteria, Equation 6 , is within a constant of Miche's expression, Equation 4. For large slopes (i.e. limiting case $A=\pi / 2)$, the factor $\sin (A)$ differs from $A$ by 50 percent.

An additional dimensionless grouping $d / L_{o}$ can be formed by dividing the first RHS parameter grouping by the second parameter grouping. This grouping of parameters has the advantage of delineating the relative water depth which the structure is situated in. An important parameter for free surface flows not explicitly mentioned above is Froude number, which for oscillatory flows in deep water can be represented as the multiplication of the first two RHS groupings in Equation 1.

A second method of obtaining dimensionless variable groupings of importance is by casting the physical equations into dimensionless form. The basic equations of fluid dynamics would point out the importance of Reynolds number, Froude number, and Webber number as before. To obtain further groupings of importance, a direct look at physical equations for runup due to nonbreaking waves is called for.

Koh and LeMehaute (1966) have suggested a runup equation for sloped structures of the form: 


$$
R / H=(\pi / 2 A)^{1 / 2}+(\pi H / L)(1 / \tanh (k d))\left(1+3 / 4 \sinh ^{2}(k d)-1 / 4 \cosh ^{2}(k d)\right)
$$

The first term is based on an earlier linear expression derived by Miche (1951) for deep water conditions, while the following terms are based on Miche's (1951) approximation to non-breaking runup on vertical walls for nonlinear wave theory. Except for a missing linear shoaling coefficient the first part of this expression agrees with that of Keller (1961) which was derived for non-plane beds with non steep slopes.

Keller and Keller (1965) derived an expression for the case of a plane slope and horizontal bottom using linear long wave theory with the result:

$$
R / H=\left[J O\left(\left(k_{o} d\right)^{1 / 2} / A\right)+J 1\left(\left(k_{o} d\right)^{1 / 2} / A\right)\right]^{-1 / 2}
$$

where JO and $\mathrm{J} 1$ are Bessel functions of the zero and first order respectively. In both the above expressions for non-breaking wave runup, the relative runup is seen to be of the functional form:

$$
R / H=f\left(A, d / L_{0}, H / L_{0}\right)
$$

The grouping of the parameters on the RHS of equation 9 can also be combined and reexpressed as before:

$$
R / H=f\left(A /\left(H / L_{0}\right)^{1 / 2}, d / L_{0}\right)
$$

where the first dimensionless grouping is of a similar form to the modified Iribarren number used previously.

In an attempt to unify the presentation of relative runup on smooth slopes, the primary independent variable of importance was chosen to be the modified Iribarren number. 


\section{$\underline{\text { Results }}$}

Relative runup plots for nine slopes ranging from vertical to 1 on 10 have been presented in Figures 1 thru 9. The expected criteria for breaking waves given by the modified Hunt (1959) expression

$$
R / H=\sin (A) /\left(H / L_{0}\right)^{1 / 2}
$$

is superimposed on the plots along with an upper limit expression of the Miche-Keller form (Equations 2 and 4) for non-breaking wave limit. The expression for this upper limit found to be most consistent with the data is given by:

$$
R / H=(2 \pi)^{1 / 2}(\pi / 2 A)^{1 / 4}
$$

If the shoaling coefficient $K_{3}$ is assumed to be unity, this expression is consistent with Eq. 4 (except for a constant $(=2.0$ )) and with Eq. 6 (using Sin(A) rather than A). Table 2 presents this relative runup upper limit versus structure slope for the slopes investigated in this study. The rationalization for this approach to maximum wave runup is that within the realm of breaking waves (on the slope) the relative runup should follow the modified Iribarren number. As the modified Iribarren number is increased and enters the zone of non-breaking, the relative runup should decrease, therefore limits provided should envelope runup data.

In all cases the data in the breaking zone portion of the curve follow the modified Iribarren number relationship well. Additionally, the critical transition point for nonbreaking describes well the upper limit of the relative runup except for the 1 on 10 and vertical slope where it overestimates. The reason for this overestimation on the 1 on 10 slope is not entirely known but believed to be due in part to the greater effect of friction as slope gets milder and the consequent opportunity for a viscous boundary layer to develop. The upper limit for relative runup on a smooth vertical slope according to Eq. (12) is: 


$$
R / H=(2 \pi)^{1 / 2}=2.5
$$

A simple periodic standing wave on a vertical slope would produce an expression with relative runup $\mathrm{R} / \mathrm{H}=1.0$. Additionally, Wallace (1964) provided a method to numerically calculate the runup for solitary waves (which can be considered to be a limiting case of periodic waves in shallow water). For vertical walls with $\mathrm{H} / \mathrm{d}>0.15$ his method produces an estimated $\mathrm{R} / \mathrm{H}=2.5$ in accord with the above proposed criterion. A value of relative runup $R / H=2.5$ on vertical waves is not inconsistent with laboratory findings of Takada (1974) or the original recommended value of $\mathrm{R} / \mathrm{H}=3.0$ proposed by Hunt (1959) for surging (non-breaking) waves.

Although graphs have not been included in the present paper, the approach has been used on one set of data with a 1 on 3 slope in $29.5 \mathrm{~cm}$ water depth and is consistent with the results provided herein.

\section{Conclusions}

A method is presented for estimating the upper limit of periodic wave runup on smooth sloped coastal structures. The method is simple and can be applied in an unambiguous manner to a wide range of slopes. Essentially, the method is composed of two elements, a modified surf parameter and a limiting

value for relative runup caused by non-breaking wave conditions. The modified surf parameter allows vertical structures to be included in the analysis which would be impossible with the standard surf parameter, Battjes (1974). For structures with steep slopes or vertical, where non-breaking wave conditions dominate, the method provides a logical envelope for the runup data. On somewhat flatter slopes where a mixture of wave conditions occur, the method predicts the runup of breaking waves quite well and gives a reasonably conservative envelope for the runup of non-breaking waves. Minor modifications of the method might be required for non-breaking conditions on flat slopes to ensure against gross over-prediction. 


\section{References}

Battjes, J. A. (1974). "Computation of Set-Up, Longshore Currents, Runup and Overtopping Due to Wind Generated Waves." PhD Dissertation, Technische Hogeschool, Delft, Netherlands.

Galvin, C. J., Jr. (1972). "Wave Breaking in Shallow Water," Waves on Beaches, Ed. R. E. Meyer, Academic Press, pp. 413-456, New York, NY.

Fuhrboter, A. (1986). "Model and Prototype Tests for Wave Impact and Runup on a Uniform 1:4 Slope," Journal of Coastal Engineering, Vol. 10, pp. 49-84.

Hunt, I. A. (1959). "Design of seawalls and breakwaters," Proc. Journal of Waterways and Harbors Division, ASCE, Vo1. 85, WW3, pp. 123-152, September 1959, New York, NY.

Iribarren, C. R. and Nogales, C. (1949). "Protection des Ports, Section II," Comm. 4, XVIIth Int. Navigation Congress, pp. 31-80, Lisbon, Portugal.

Keller, J. B. (1961). "Tsunamis-water waves produced by earthquakes, " Tsunami Hydrodynamics Conference, Honolulu, Hawaii.

Keller, J. B. and Keller, H. B. (1965). "Water wave runup on a beach," Part II, Office of Naval Research, DDC, No. AD 623136, Washington, DC.

Koh, R. C. Y. and LeMehaute, B. (1966). "Final Report; Volume II: Wave Runup State of the Art," Report S-245B, National Engineering Science Company, Pasadena, CA.

Miche, R. (1951). "Le pouvoir reflechissant des ouvrages maritimes exposes a l'action de la houle," Annales des Ponts et Chaussees, 121e Annee, pp. 285-319, May-June 1951.

Munk, W. H. and Wimbush, M. (1969). "A rule of thumb for wave breaking," Oceanology, Vo1. 9, pp. 56-69.

Raichlen, F. and Hammack, J. L., Jr. (1974). "Runup Due to Breaking and Nonbreaking Waves," Proc. 14th Coastal Engineering Conference, pp. 1937-1955, ASCE, New York, NY.

Savage, R. P. (1958). "Wave Runup on Roughened and Permeable Slopes," Jour nal of the Waterways and Harbors Division, ASCE, Vo1. 84, No. WW3, May 1958, New York, NY.

Saville, T., Jr. (1956). "Wave Runup on Shore Structures," Journal of the Waterways and Harbor Division, ASCE, Vol. 82, No. WW2, April 1956, New York, NY.

Saville, T., Jr. (1958). "Large Scale Model Tests of Wave Runup and Overtopping, Lake Okeechobee Levee Sections," Unpublished Manuscript, US Army Corps of Engineers, Beach Erosion Board, Washington, DG. 
Stoa, P. N. (1978). "Reanalysis of Wave Runup on Structures and Beaches," Technical Paper No. 78-2, US Army Corps of Engineers, Coastal Engineering Research Center, March 1978, Washington, DC.

Technical Advisory Committee on Protection Against Inundation. (1974). "Wave Runup and Overtopping," Government Publishing Office, The Hague, Netherlands.

Takada, A. (1974). "Estimation of Wave Overtopping Quantity Over Sea Walls," Proc. 14th Coastal Engineering Conference, pp. 1996-2014, ASCE, New York, NY.

US Army Corps of Engineers. (1984). Shore Protection Manual, Coastal Engineering Research Center, US Government Printing Office, Washington, DC.

Van Dorn, W. G. (1966). "Runup recipe for Periodic Waves on Uniformly Sloping Beaches," Proceedings of the 10th Coastal Engineering Conference, ASCE, pp. 349-363, New York, NY.

Wallace, N. R. (1964). "Deformation of solitary waves, Part II: Shoaling," Report No. URS 631-2, May 1964. 
Table 1

Summary of Test Conditions

\begin{tabular}{|c|c|c|c|c|c|c|}
\hline $\begin{array}{c}\text { Structure } \\
\text { Slope } \\
\end{array}$ & $\begin{array}{l}\text { Wave } \\
\text { Height } \\
\text { (cm) }\end{array}$ & $\begin{array}{l}\text { Wave } \\
\text { Period } \\
(\text { sec) }\end{array}$ & $\begin{array}{c}\mathrm{R} \\
(\mathrm{cm}) \\
\end{array}$ & $\mathrm{H} / \mathrm{d}$ & $\mathrm{d} / \mathrm{L}_{\mathrm{o}}$ & $\begin{array}{c}\text { Number of } \\
\text { Observations }\end{array}$ \\
\hline vertical & $0.9-12.2$ & $0.72-4.71$ & $1.3-15.5$ & $.024-.321$ & $0.11-.471$ & 26 \\
\hline 1 on 0.5 & $0.9-18.6$ & $0.72-4.71$ & $1.1-37.2$ & $.025-.488$ & $.011-.471$ & 33 \\
\hline 1 on 1.0 & $0.9-18.6$ & $0.72-4.71$ & $0.9-42.8$ & $.022-.488$ & $.011-.471$ & 32 \\
\hline 1 on 1.5 & $1.2-17.1$ & $0.72-4.71$ & $1.2-39.6$ & $.030-.448$ & $.011-.658$ & 45 \\
\hline 1 on 2.25 & $0.9-17.4$ & $0.72-4.71$ & $1.5-45.8$ & $.028-.456$ & $.011-.658$ & 51 \\
\hline 1 on 3 & $0.9-17.7$ & $0.72-4.71$ & $2.4-48.4$ & $.023-.464$ & $.011-.658$ & 49 \\
\hline 1 on 4 & $0.9-18.3$ & $0.72-4.71$ & $2.3-47.5$ & $.028-.480$ & $.011-.658$ & 51 \\
\hline 1 on 6 & $0.8-17.8$ & $0.72-4.71$ & $1.8-37.2$ & $.021-.468$ & $.011-.658$ & 51 \\
\hline 1 on 10 & $0.5-12.1$ & $0.72-4.71$ & $0.8-8.9$ & $.013-.480$ & $.011-.471$ & 28 \\
\hline
\end{tabular}

Table 2

Maximum Relative Runup Versus Structure S1ope

\begin{tabular}{lc}
\hline \multicolumn{1}{c}{ Slope } & R/H (equation 12) \\
vertical & 2.50 \\
$1: 0.5$ & 2.73 \\
$1: 1$ & 2.97 \\
$1: 1.5$ & 3.19 \\
$1: 2.25$ & 3.49 \\
$1: 3$ & 3.70 \\
$1: 4$ & 3.95 \\
$1: 6$ & 4.39 \\
$1: 10$ & 5.00 \\
\hline
\end{tabular}




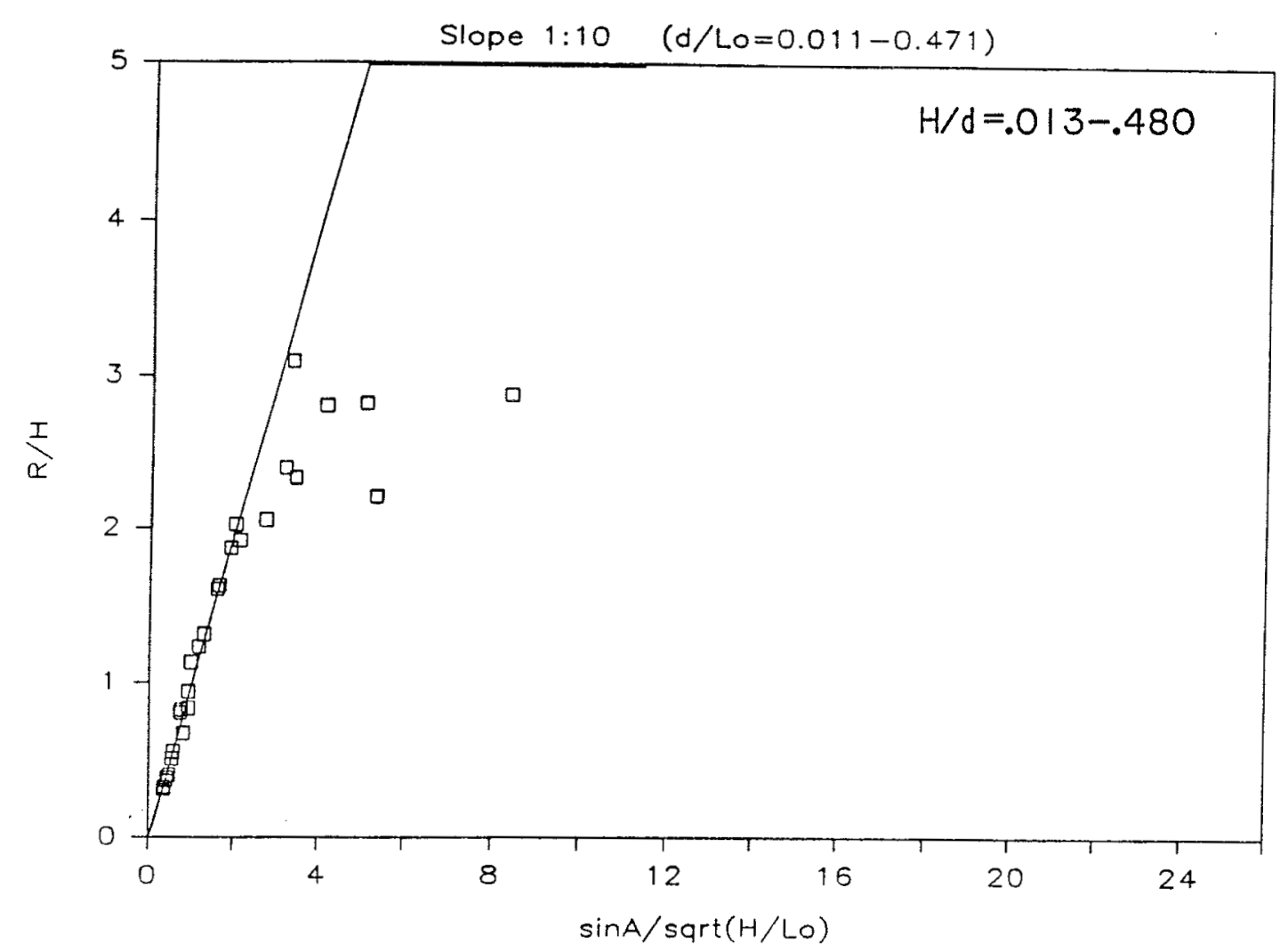

Figure 1. Relative runup versus modified Iribarren number, slope 1:10

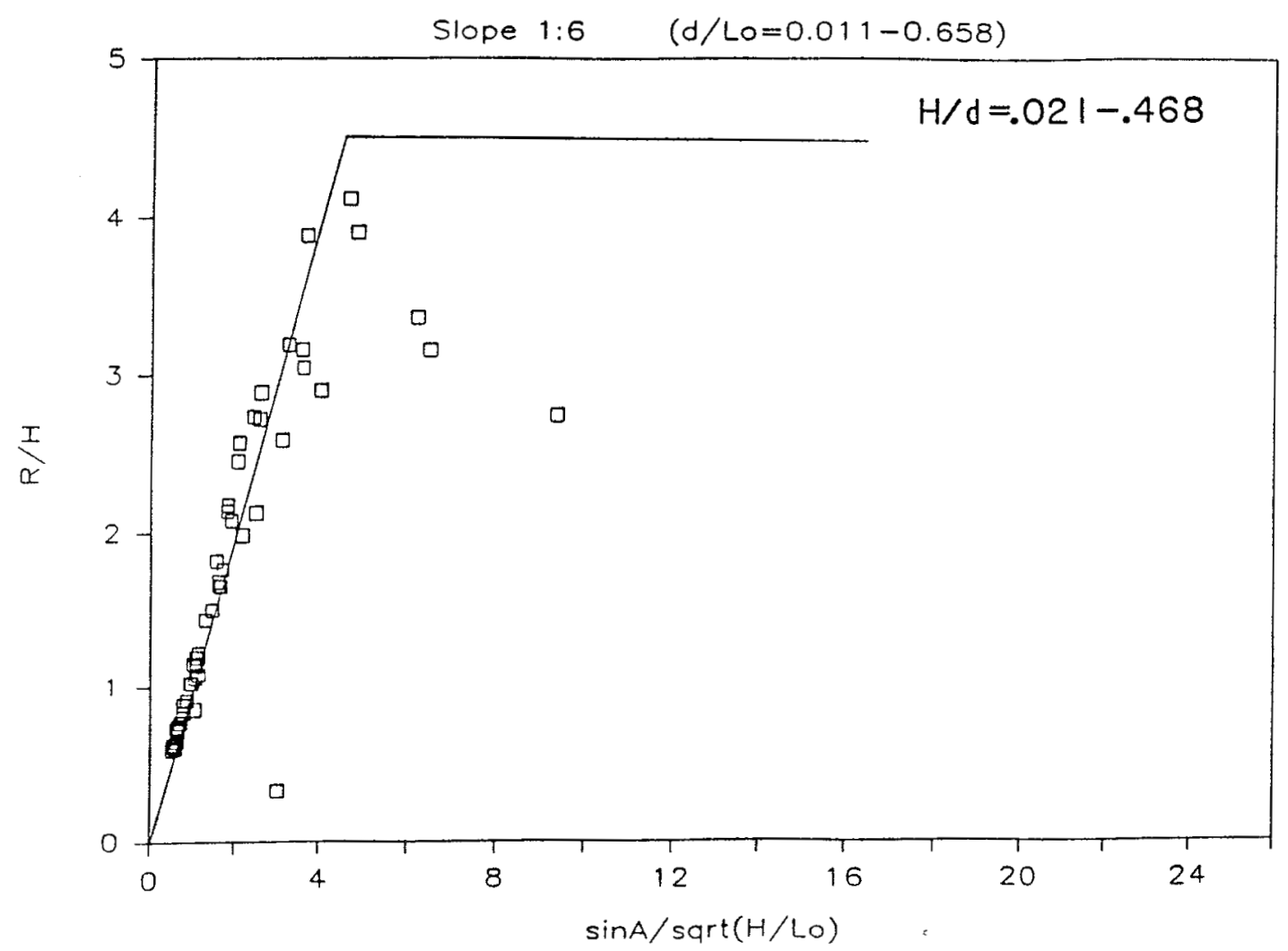

Figure 2. Relative runup versus modified Iribarren number, slope 1:6 


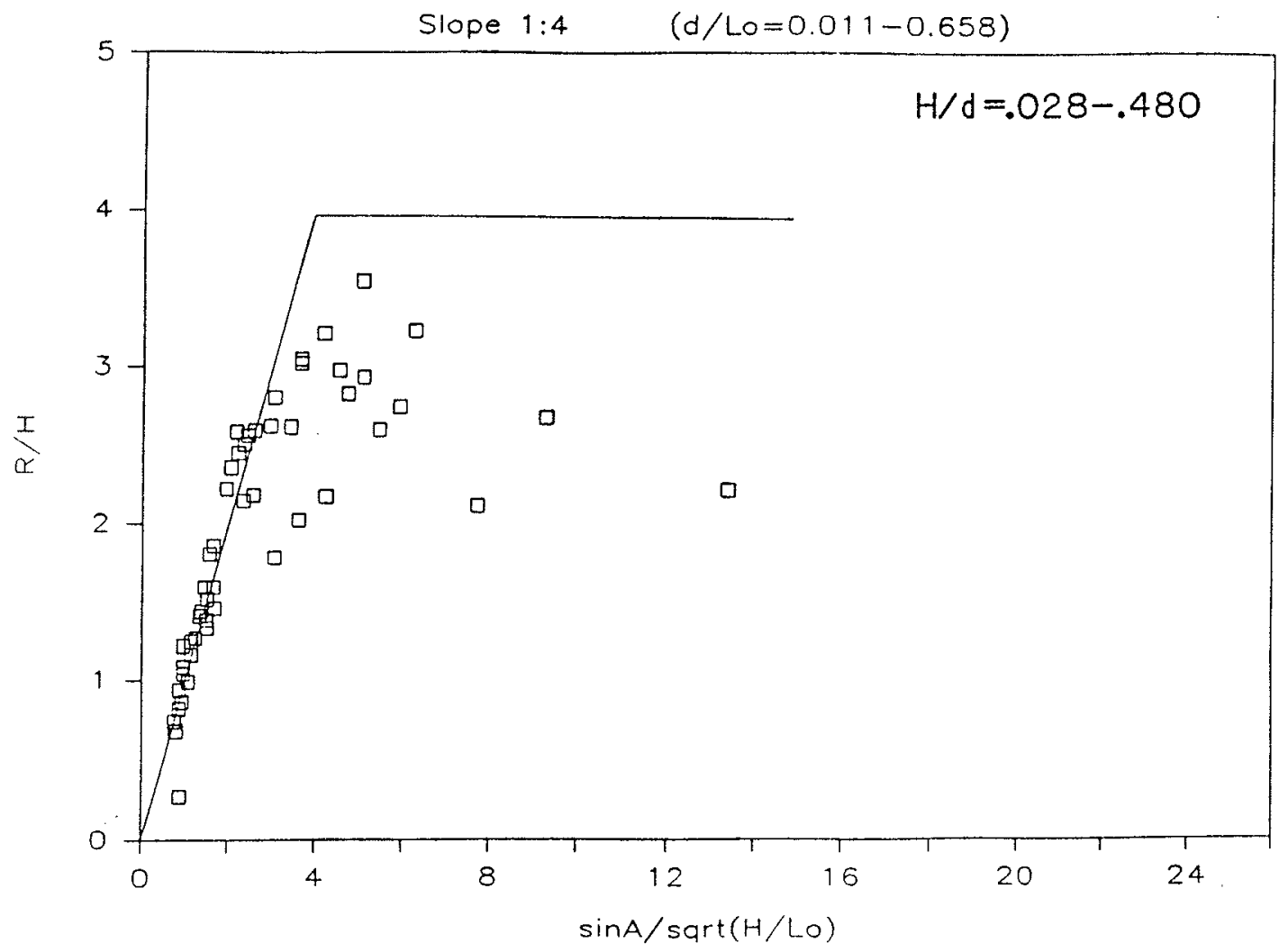

Figure 3, Relative runup versus modified Iribarren number, slope 1:4

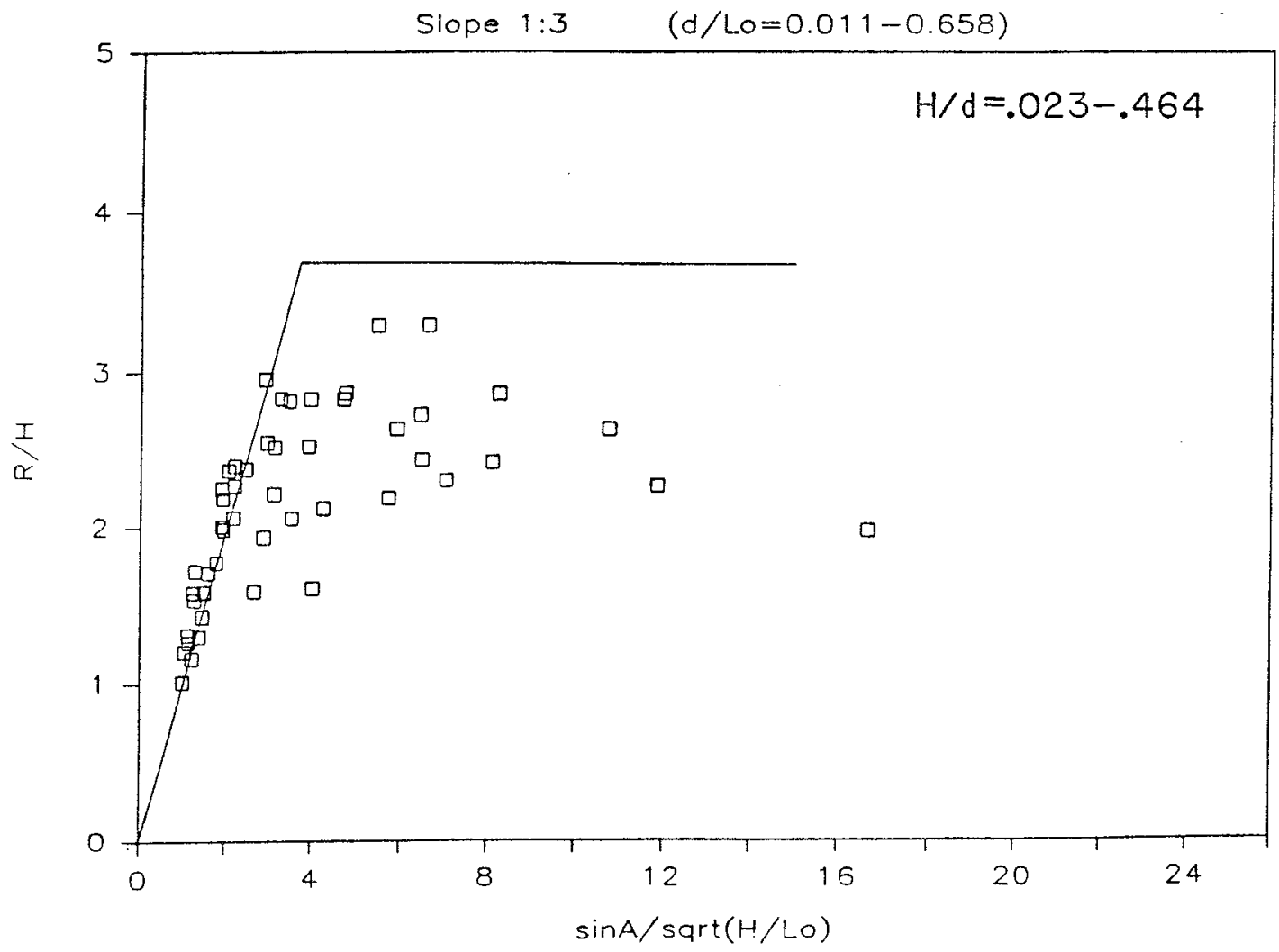

Figure 4. Relative runup versus modified Iribarren number, slope 1:3 


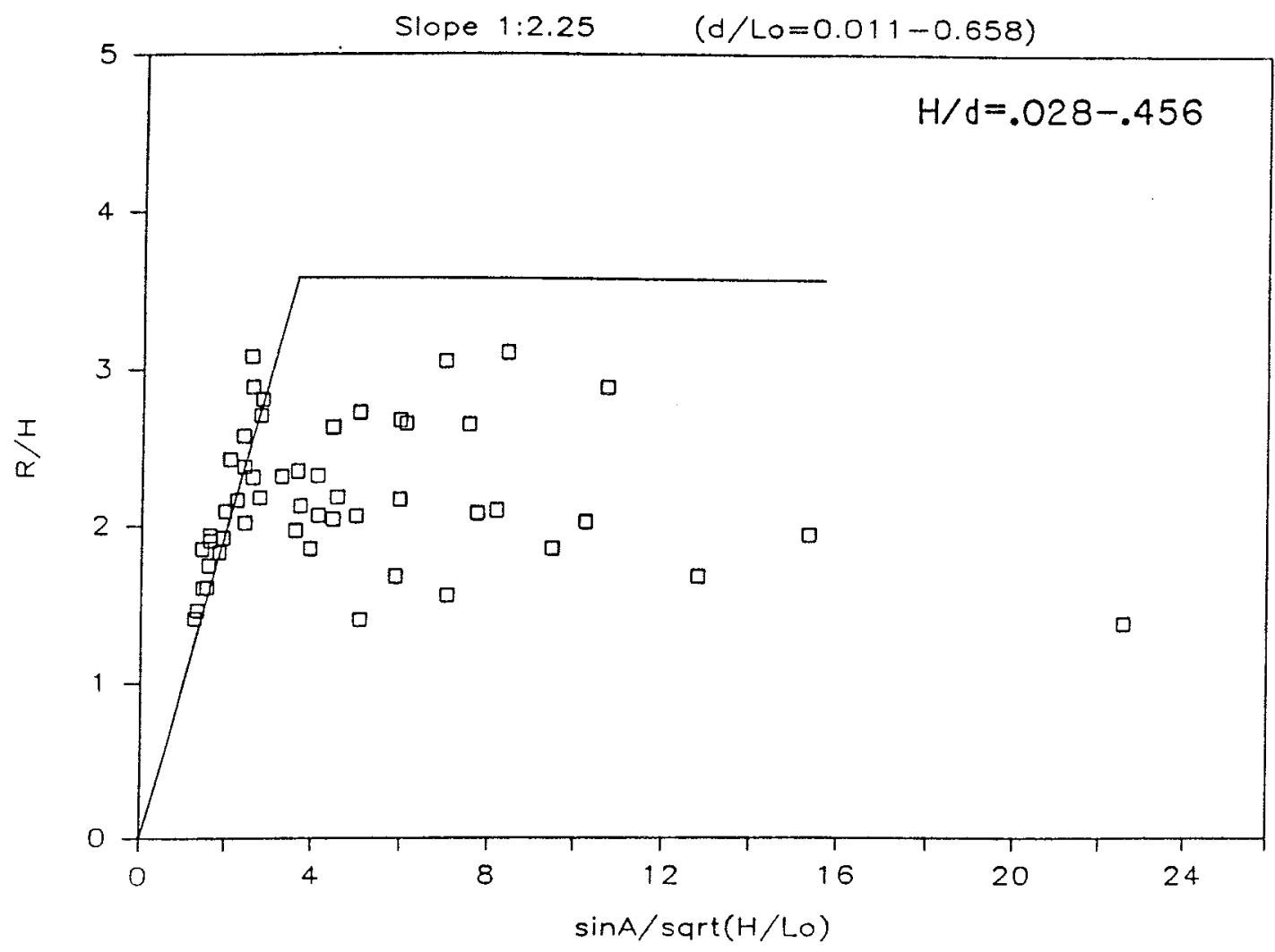

Figure 5. Relative runup versus modified Iribarren number, slope 1:2.25

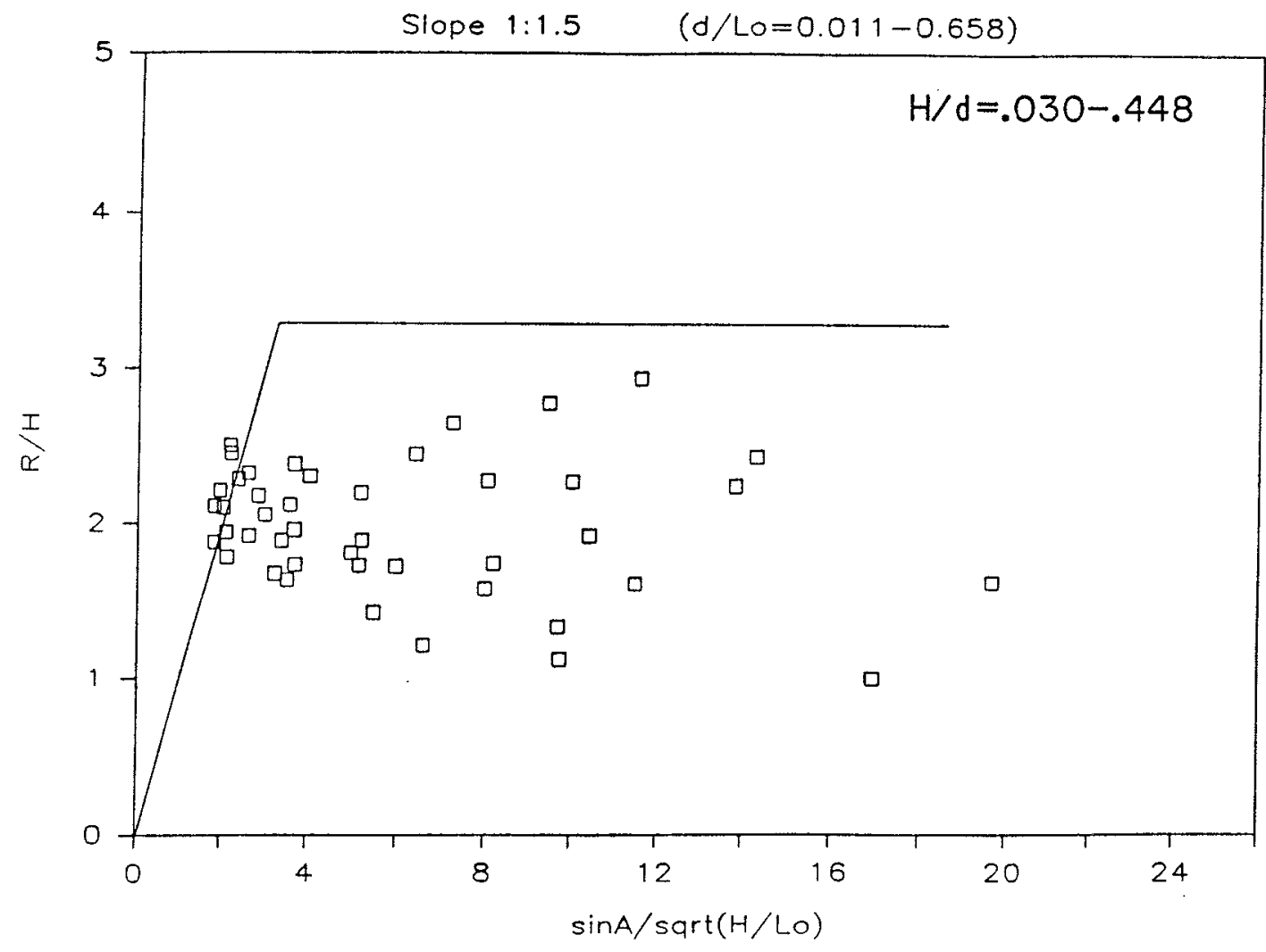

Figure 6. Relative runup versus modified Iribarren number, slope $1: 1.5$ 


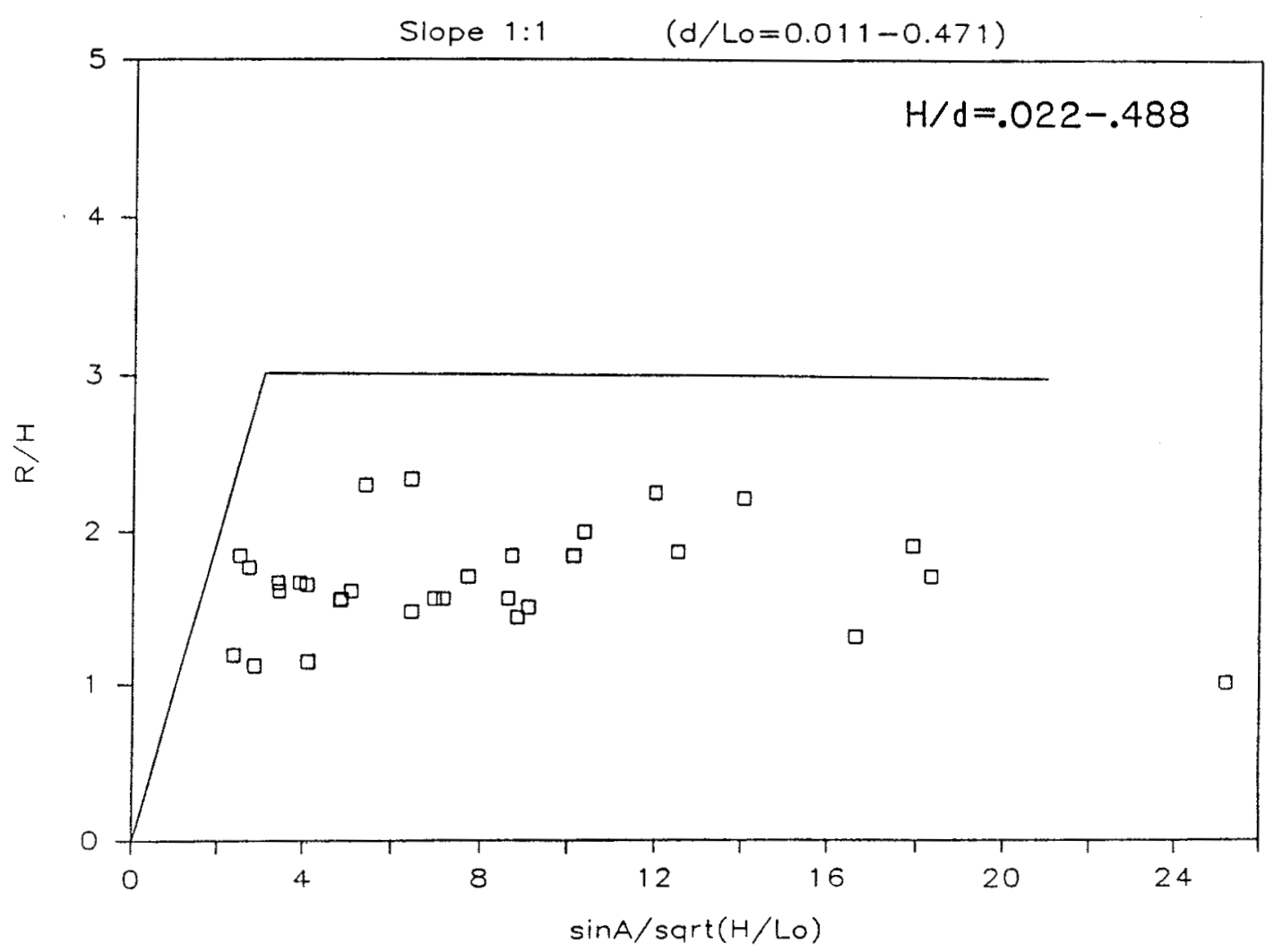

Figure 7. Relative runup versus modified Iribarren number, slope 1:1.

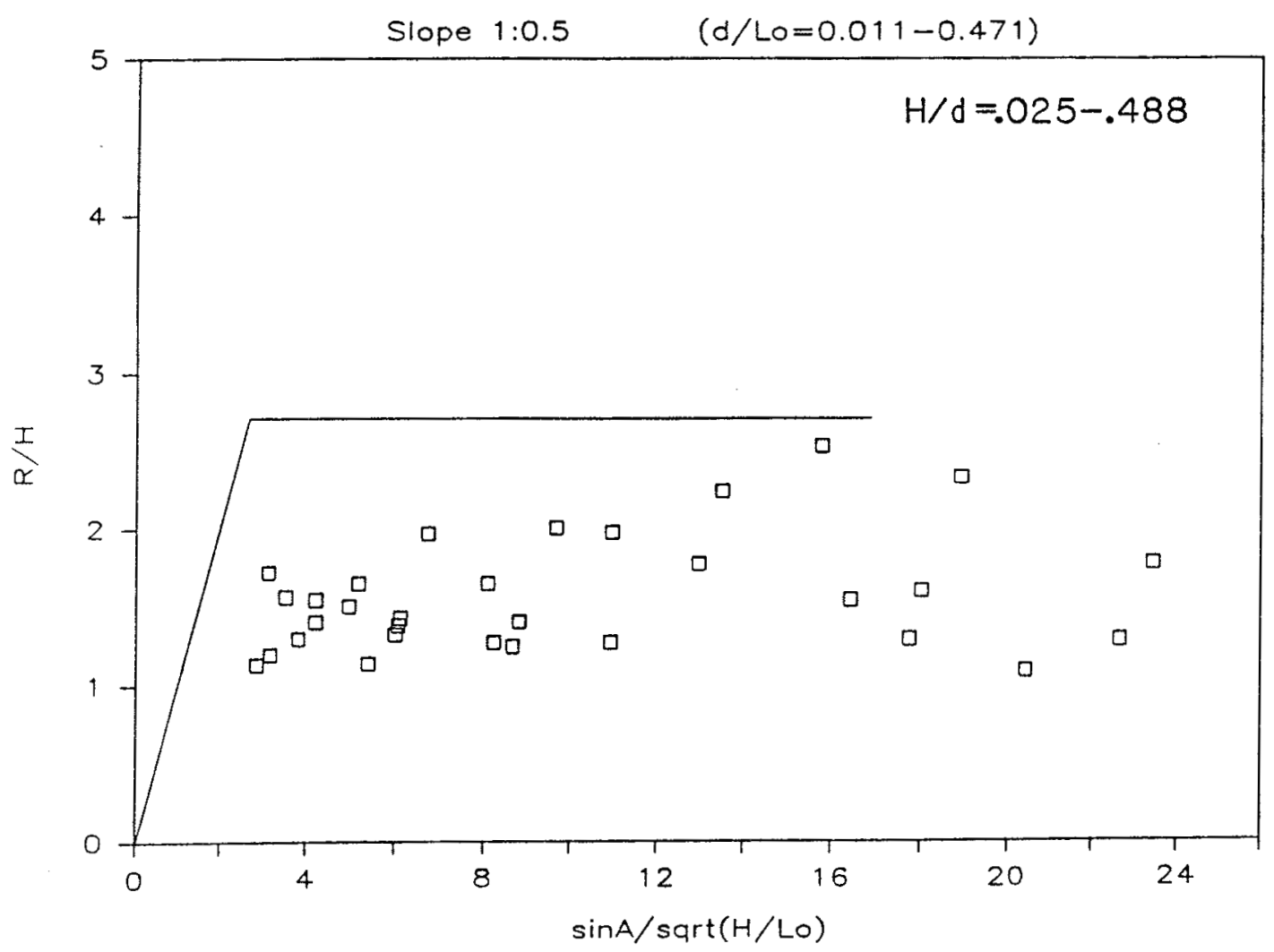

Figure 8. Relative runup versus modified Iribarren number, slope 1:0.5 


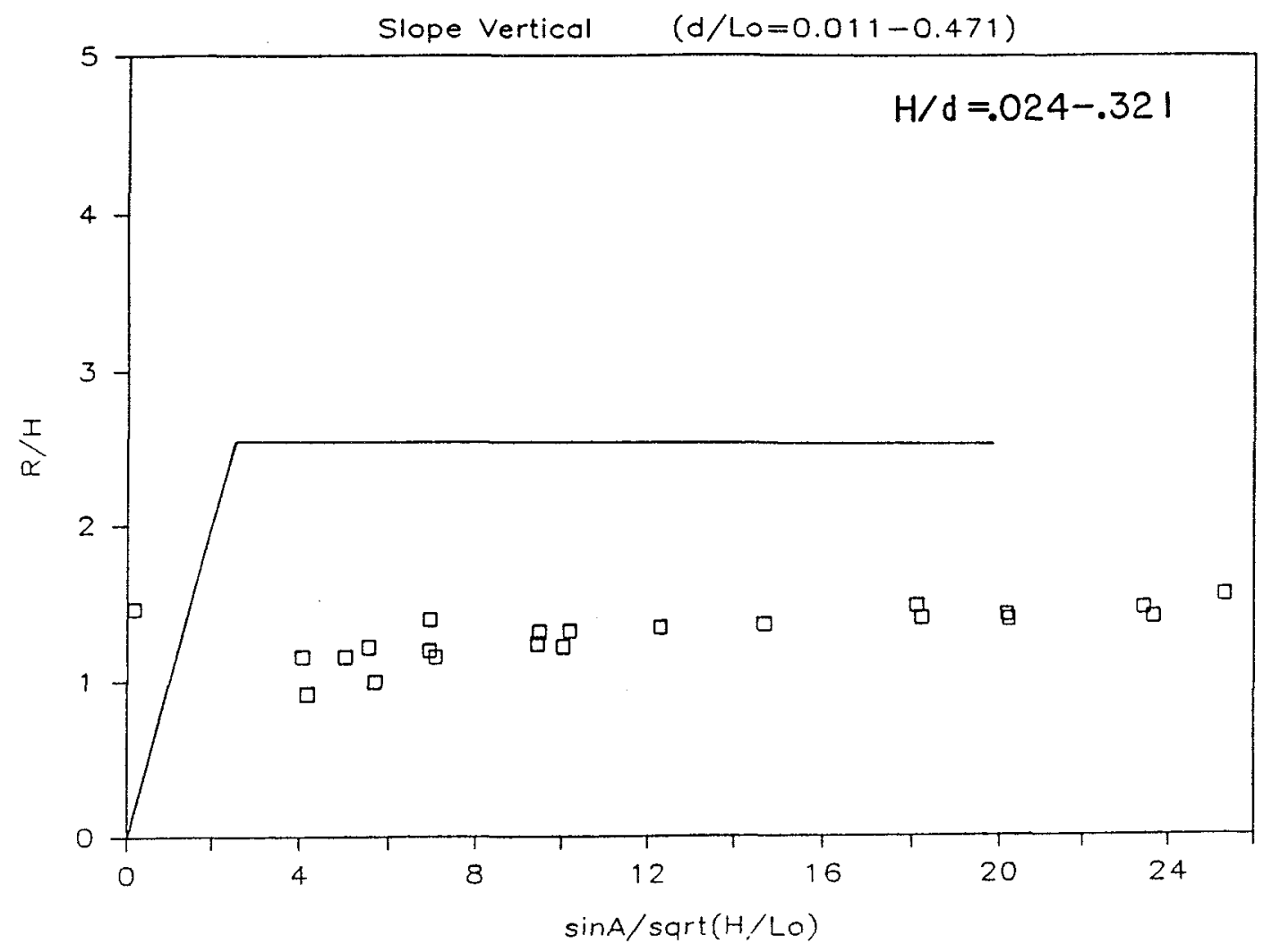

Figure 9. Relative runup versus modified Iribarren number, slope vertical 
Appendix A: Notation

The following symbols are used in this paper:

$A$ - angle of structure slope with horizontal;

$\mathrm{H}, \mathrm{H}_{\mathrm{o}}$ = wave height (at toe of structure), deepwater wave height;

$\mathrm{K}_{\mathrm{s}}$ = linear wave theory shoaling coefficient;

$\mathrm{L}, \mathrm{L}_{\mathrm{O}}=$ wavelength, deepwater wavelength;

R - runup;

$\mathrm{T}=$ wave period;

$d$ = water depth (at toe of structure)

$f()=$ function of;

$g$ = gravitational acceleration;

$k, k_{0}$ - wavenumber; deep water wavenumber

$\rho$ - water density;

$\mu=$ dynamic viscosity; and

$\sigma=$ surface tension. 